\section{A Comperative Evaluation of 3 Different Polishing Methods on Tooth Surface Roughness}

\section{Abstract}

Objective: The objective of this study is to evaluate the effect of three different polishing procedures on surface roughness occuring after sonic scaling.

Material and Methods: Dental calculus on 60 extracted teeth stored in distilled water was removed using a sonic device. Surface roughness was measured by profilometer and then samples were divided into 3 groups. Polishing was applied to the samples in first group by rotary rubber cup and prophylaxis paste, to the samples in second group by air-flow, and to the samples in third group by stainbuster bur. The surface roughness measurements taken were recorded by profilometer at every stage.

Results: A significant reduction was determined in surface roughness in the groups used prophylaxis paste and stainbuster bur and the reduction was similar between these groups. In the group used air-flow, a significant reduction could not be detected in the surface roughness.

Conclusion: Stainbuster bur may be an alternative method for traditional polishing material, because of providing the ease of application such as air-polishing techniques and providing smooth surfaces like prophylaxis paste.

Clinical Relevance: Stainbuster bur may be an alternative method for traditional polishing material, because of providing the ease of application such as airpolishing techniques and providing smooth surfaces like prophylaxis paste.

Keywords: Air polishing; Periodontal health; Polishing materials; Stainbuster; Surface roughness; Tooth polishing

\section{Neyran Yillmaz Tuzcel Murat Akkaya and Fatma Karacaoglu,}

Department of Periodontology, Ankara University, Ankara, Turkey

\section{Corresponding author: \\ Dr. Fatma Karacaoglu}

\section{fboke@ankara.edu.tr}

Research Assistant, Faculty of Dentistry, Department of Periodontology, Ankara University, Çankaya 06500, Ankara, Turkey.

Tel: +903122965685

Fax: +903122123954

Citation: Tuzcel NY, Akkaya M. A, Karacaoglu $\mathrm{F}$, Comperative Evaluation of 3 Different Polishing Methods on Tooth Surface Roughness. J Biomedical Sci. 2016, 6:1.

Received: October 27, 2016; Accepted: November 08, 2016; Published: November 16, 2016

\section{Introduction}

In develop countries, people live longer and keep their natural teeth longer compared to their ancestors. This development depends on decreased tooth decay and the incidence of periodontitis due to better motivation, improved home care habits and lifelong maintenance program [1,2].

The one of foundations in providing and maintaining the periodontal health is that the bacteria and their products remove from the dental tissue and that the surface is smoothed by giving minimal damage to the dental tissue. However, iatrogenic effects of professional instrumentation have been shown in several in vitro studies. The unwanted surface irregularities make it difficult to remove daily plaque by increasing the plaque formation and bacteria colonization $[3,4]$. For this reason, many authors recommend the polishing following this application [5-7]. On the other hand, repetitive polishing applications causes the loss of material on the tooth surface $[3,4,8-10]$.

Today, the most widely used polishing material is rotary rubber cup, pumice or prophylaxis paste. This method often creates disappointment in settled colorations, it requires a long time and is tiring for the detist. In order to be able to make the process faster and more efficiently, the one of the devices developed is the air-flow polishing instrument ejecting compressed air, water and sodium bicarbonate. Both of these methods have advantages and disadvantages. In this study, stainbuster burs were evaluated as the new material for polishing. These burs were made of glass 
fiber reinforced resins that were enriched by zircon. They were designed for removing the colored layers, stains and cement from enamel surface. The surface characteristics of stainbuster burs is abrasive power of fiber structure covering the entire work surfacer and divided into small fragments, when it contacts with a hard surface. While resin matrix is used, fibers occur, therefore it also has the self-sharpening feature. Stainbuster burs become sharp by itself, and the characteristics of abrasive are permanent. However, they slide over the tissues such as fibromatosis gingival membranes without cutting or trimming and they do not impact on soft tissue.

The objective of this study is to evaluate the effect of three different polishing methods in reducing the tooth surface roughness occuring after sonic scaling.

\section{Materials and Methods}

\section{Experimental design}

In the study, 60 mandibular incisors extracted for periodontal or prosthetic reasons, and had plaque and calculus on their lingual surfaces were used. After extracting, patients were informed that their teeth would be used in this study and verbal consent was obtained.

After the extracted tooth were washed under running water for 1 minute, it was maintained in distilled water. All tooth were scaled by the same researcher by using the ultrasonic device (Satelect; France) in contact with the lateral surface of teeth, in fasio-lingual direction and with light pressure.

The scaling was stopped when the test area seemed smooth and clean by visual inspection. Following the completion of scaling process, tooth were randomly divided into 3 groups so that 20 teeth are in each group.

Root surfaces of teeth were removed by cutting from cementoenamel junction, as the measurement of roughness was only limited to the enamel surface. Groups were fixed in otopolymerizan acrylic to be 20 teeth in each table so that the measurements could be performed quickly and accurately. Teeth in this tables were evaluated in terms of surface roughness by profilometer (Perthomer M2; Mahr, Gottingen, Germany) without knowing which group there were included.

Profilometer measurements include $\mathrm{Ra}, \mathrm{Rq}, \mathrm{Rz}, \mathrm{Rmax}$ and $\mathrm{Rt}$ values and surface graphics. These values are:

Ra: Arithmetic average of Ra values in roughness profile

$\mathrm{Rq}$ : Geometric average of the deviations occuring in roughness profile

Rz: Average height of peak-to-valley

Rmax: Maximum roughness depth

Rt: Roughness depth

In first group (G1), each tooth was polished by using prophylaxis paste (Clinpro Prophy Paste; 3M ESPE, St. Paul, MN, USA) and rotary rubber cup during 5 seconds. Clinician did not apply extra force, it was solely provided the contact with by own weight of the device. Second group (G2) was polished by using air-flow (KaVo prophyflex 3; USA and Clinpro Prophy Powder; 3M ESPE, St. Paul, MN, USA) during 5 seconds. While using, the device was held at right angles to the applied tooth surface and 1-1,5 $\mathrm{cm}$ away in average. In third group (G3), teeth were polished again by using stainbuster bur (Stain Buster, Carbotech, Ganges, France) during 5 seconds.

Samples were evaluated by profilometer once again in order to be able to evaluate the changes in surface roughness. Profilometer measurements were taken for 3 times in order to be able to minimize the margin of error and the average of these measurements was used in this statistical evaluation.

\section{Results}

According to the descriptive statictics, the groups showed normal distibution. For the samples in 3 groups consisting of 20 teeth in each one, $R a, R q, R z, R$ max and $R t$ values measured at the begining and after treatment were shown in Table 1. In Ra, Rq, Rz, Rmax and $\mathrm{Rt}$ values recorded in the begining measurements, there was no significant difference between groups ( $p>0.05)$. In the measurements following the polishing application, there was a significant difference between groups in $R a(p<0.05), R q(p<0.05)$, and $R z(p=0.05)$ values, whereas the difference between Rmax and $R t$ values were not statistically significant ( $p>0.05$ ) (Table 2).

Following the polishing application, it was observed that Ra values decreased in 15 samples of G1, 11 samples of $G 2$ and

Table 1 Surface roughness measurements at baseline and after polishing (B; baseline measurement, L; last measurement).

\begin{tabular}{|c|c|c|c|}
\hline & G1 & G2 & G3 \\
\hline RaB & $0,784 \pm 0,08$ & $0,716 \pm 0,07$ & $0,698 \pm 0,08$ \\
\hline RqB & $1,164 \pm 0,12$ & $0,940 \pm 0,08$ & $1,016 \pm 0,13$ \\
\hline RzB & $4,445 \pm 0,50$ & $3,292 \pm 0,30$ & $3,879 \pm 0,55$ \\
\hline RmaxB & $7,910 \pm 1,02$ & $5,141 \pm 0,47$ & $6,641 \pm 0,94$ \\
\hline RtB & $8,269 \pm 1,02$ & $5,519 \pm 0,45$ & $7,144 \pm 0,99$ \\
\hline RaL & $0,576 \pm 0,07$ & $0,746 \pm 0,07$ & $0,526 \pm 0,04$ \\
\hline RqL & $0,753 \pm 0,09$ & $1,009 \pm 0,11$ & $0,694 \pm 0,05$ \\
\hline RzL & $2,671 \pm 0,39$ & $3,459 \pm 0,41$ & $2,371 \pm 0,21$ \\
\hline RmaxL & $3,736 \pm 0,51$ & $5,943 \pm 0,98$ & $3,745 \pm 0,38$ \\
\hline RtL & $4,312 \pm 0,62$ & $6,375 \pm 0,98$ & $4,186 \pm 0,37$ \\
\hline
\end{tabular}

Table 2 Comparision of the data obtained at the beginning and at the end of the research.

\begin{tabular}{|c|c|c|c|}
\hline & Ki-square & df & Asymp. Sig \\
\hline RaB & 0,592 & 2 & 0,774 \\
\hline RqB & 1,223 & 2 & 0,543 \\
\hline RzB & 2,117 & 2 & 0,347 \\
\hline RtB & 3,663 & 2 & 0,16 \\
\hline RaL & 3,369 & 2 & 0,186 \\
\hline RqL & 6,731 & 2 & 0,035 \\
\hline RzL & 6,695 & 2 & 0,035 \\
\hline RmaxL & 5,777 & 2 & 0,056 \\
\hline RtL & 4,287 & 2 & 0,117 \\
\hline
\end{tabular}


16 samples of G3 compared to the values before the polishing application. In the last measurement of $\mathrm{Rq}$ values, it was observed that Ra values decreased in 14 samples of $\mathrm{G} 1$, in 10 samples of $\mathrm{G} 2$ and 15 samples of G3, compared to the values before the polishing application. In the last measurement of $\mathrm{Rz}$ values, it was observed that Ra values decreased in 16 samples of $\mathrm{G} 1,10$ samples of $\mathrm{G} 2$ and 16 samples of $\mathrm{G} 3$ compared to the values before the polishing application. It was observed that the decrease was not statictically significant in 16 samples of $\mathrm{G} 1$, in 10 samples of $\mathrm{G} 2$ and in 16 samples of $\mathrm{G} 3$ for Rmax values; and respectively in 14, 15 and 10 samples for Rt values compared to the values before polishing application (Tables 3a-3c).

\section{Discussion}

The objective of this study is to compare the amounts of roughness reduction in different materials used in polishing process that was performed for reducing the roughness resulting during the scaling and root planning process; hence it can be compared to the efficacy of their clinical use.

The first study showing that there was no difference between manual applications and ultrasonic devices in terms of the activity was done by Badersten et al. [11] and then it was supported by so many studies [11-18]. It was agreed that sonic and ultrasonic devices provided similar clinical results with the scaling and root planning process in the American Academy of Periodontology 1996 world workshop' [14].

Although similar results were obtained between hand devices and sonic/ultrasonic devices in terms of the effectiveness and

Table 3a Alteration of surface roughness values before and after polishing in group 1.

\begin{tabular}{|c|c|c|c|}
\hline GROUP & & & $\mathbf{N}$ \\
\hline \multirow{20}{*}{ G1 } & \multirow{4}{*}{ RaL-RaB } & Negative Ranks & $15^{\mathrm{a}}$ \\
\hline & & Positive Ranks & $5^{b}$ \\
\hline & & Ties & $0^{c}$ \\
\hline & & Total & 20 \\
\hline & \multirow{4}{*}{$R q L-R q B$} & Negative Ranks & $14^{\mathrm{d}}$ \\
\hline & & Positive Ranks & $6^{e}$ \\
\hline & & Ties & $0^{f}$ \\
\hline & & Total & 20 \\
\hline & \multirow{4}{*}{ RzL-RzB } & Negative Ranks & $16^{\mathrm{g}}$ \\
\hline & & Positive Ranks & $4^{h}$ \\
\hline & & Ties & $0^{i}$ \\
\hline & & Total & 20 \\
\hline & \multirow{4}{*}{ RmaxL-RmaxB } & Negative Ranks & $16^{j}$ \\
\hline & & Positive Ranks & $4^{k}$ \\
\hline & & Ties & $0^{\prime}$ \\
\hline & & Total & 20 \\
\hline & \multirow{4}{*}{ RtL-RtB } & Negative Ranks & $14^{\mathrm{m}}$ \\
\hline & & Positive Ranks & $6^{n}$ \\
\hline & & Ties & $0^{\circ}$ \\
\hline & & Total & 20 \\
\hline
\end{tabular}

a: RaL <RaB, b: RaL $>\operatorname{RaB}, \mathrm{c}: \operatorname{RaL}=\operatorname{RaB}, \mathrm{d}: \mathrm{RqL}<\mathrm{RqB}$, e: RqL $>\operatorname{RqB}, \mathrm{f}: \mathrm{RqL}=\mathrm{RqB}$, g: $R z L<R z B, h$ : RzL $>R z B$, i: RzL=RzB, j: RmaxL $<R \max B, k$ : RmaxL $>R \max B$, I:RmaxL=RmaxB, m:RtL<RtB, n:RtL>RtB, o:RtL=RtB.
Table 3b Alteration of surface roughness values before and after polishing in group 2.

\begin{tabular}{|c|c|c|c|}
\hline GROUP & & & $\mathbf{N}$ \\
\hline \multirow{20}{*}{$\mathrm{G} 2$} & \multirow{4}{*}{ RaL-RaB } & Negative Ranks & $11^{\mathrm{a}}$ \\
\hline & & Positive Ranks & $9^{b}$ \\
\hline & & Ties & $0^{c}$ \\
\hline & & Total & 20 \\
\hline & \multirow{4}{*}{$R q L-R q B$} & Negative Ranks & $10^{d}$ \\
\hline & & Positive Ranks & $10^{\mathrm{e}}$ \\
\hline & & Ties & $0^{f}$ \\
\hline & & Total & 20 \\
\hline & \multirow{4}{*}{ RzL-RzB } & Negative Ranks & $10^{\mathrm{g}}$ \\
\hline & & Positive Ranks & $10^{h}$ \\
\hline & & Ties & $0^{i}$ \\
\hline & & Total & 20 \\
\hline & \multirow{4}{*}{ RmaxL-RmaxB } & Negative Ranks & $10^{j}$ \\
\hline & & Positive Ranks & $10^{k}$ \\
\hline & & Ties & $0^{\prime}$ \\
\hline & & Total & 20 \\
\hline & \multirow{4}{*}{ RtL-RtB } & Negative Ranks & $10^{m}$ \\
\hline & & Positive Ranks & $10^{n}$ \\
\hline & & Ties & $0^{\circ}$ \\
\hline & & Total & 20 \\
\hline
\end{tabular}

A: $R a L<R a B, b: R a L>R a B, c: R a L=R a B, d: R q L<R q B, e: R q L>R q B, f: R q L=R q B$ g: RzL<RzB, h: RzL>RzB, i:RzL=RzB, j: RmaxL<RmaxB, $k$ : RmaxL>RmaxB, I:RmaxL=RmaxB, $m: R t L<R t B, n: R t L>R t B, o: R t L=R t B$

Table 3c Alteration of surface roughness values before and after polishing in group 3.

\begin{tabular}{|c|c|c|c|}
\hline GROUP & & & $\mathbf{N}$ \\
\hline \multirow{20}{*}{ G3 } & \multirow{4}{*}{ RaL-RaB } & Negative Ranks & $16^{a}$ \\
\hline & & Positive Ranks & $4^{b}$ \\
\hline & & Ties & $0^{c}$ \\
\hline & & Total & 20 \\
\hline & \multirow{4}{*}{$R q L-R q B$} & Negative Ranks & $15^{d}$ \\
\hline & & Positive Ranks & $5^{e}$ \\
\hline & & Ties & $0^{f}$ \\
\hline & & Total & 20 \\
\hline & \multirow{4}{*}{ RzL-RzB } & Negative Ranks & $16^{\mathrm{g}}$ \\
\hline & & Positive Ranks & $4^{h}$ \\
\hline & & Ties & $0^{i}$ \\
\hline & & Total & 20 \\
\hline & \multirow{4}{*}{ RmaxL-RmaxB } & Negative Ranks & $16^{j}$ \\
\hline & & Positive Ranks & $4^{k}$ \\
\hline & & Ties & $0^{\prime}$ \\
\hline & & Total & 20 \\
\hline & \multirow{4}{*}{ RtL-RtB } & Negative Ranks & $15^{\mathrm{m}}$ \\
\hline & & Positive Ranks & $5^{n}$ \\
\hline & & Ties & $0^{\circ}$ \\
\hline & & Total & 20 \\
\hline
\end{tabular}

a: $\operatorname{RaL}<\operatorname{RaB}, \mathrm{b}: \operatorname{RaL}>\operatorname{RaB}, \mathrm{c}: \operatorname{RaL}=\operatorname{RaB}, \mathrm{d}: \operatorname{RqL}<\operatorname{RqB}, \mathrm{e}: \operatorname{RqL}>\operatorname{RqB}, \mathrm{f}: \operatorname{RqL}=\operatorname{RqB}$, g: RzL<RzB, h: RzL>RzB, i:RzL=RzB, j: RmaxL<RmaxB, k: RmaxL>RmaxB, I:RmaxL=RmaxB, $m: R t L<R t B, n: R t L>R t B, o: R t L=R t B$

clinical results, hand tools have been known to leave partially smoother surfaces, when surface roughness, adverse effects and contraindications were evaluated. In our study, we chose to scale 
by ultrasonic devices, because we would evaluate the reduction of roughness by using different materials after scaling process. Although hand devices were not preferred and ultrasonic devices, which smear layer formation were known to be less frequently, were used, teeth were washed under running water for $3 \mathrm{~min}$ in order to be able to be obtained the accurate measurements after scaling process.

In order to reduce the surface roughness after scaling process, various techniques and materials are used. For these materials, removal times of colorations vary by grain size of the used material and/or the applied force. In our study, periodontal prophylaxis paste and air-flow applications routinely used in clinical practice for polishing was compared to stainbuster suggested as a new polishing material.

In many study, it was shown that air-polishing devices became time-saving and effective in the application on normal enamel surface [19-23]. However, it does not generally lead to surface modification and loss of materials to be able to be detected clinically $[23,24]$. In contrast, spray may occur a significant amount of loss of material, if applied directly on root surface or dentin. As a rule, it is known that it should be certainly avoided to use these devices on dentin and cement [25]. Tissue loss caused by the technique is depends on application time, powder and water application as much as the probe distance and the application surface $[25,26]$. While we used air powder instrument in our study, the application was done by the same researcher from $1-1,5 \mathrm{~cm}$ by approaching at a right angle to the tooth surface. Likewise, the polishing application that was done by using rotary rubber cup was performed by the same researcher only by the weight of rotary instrument without extra pressure.

The one of the most commonly used polishing method is prophylaxis paste used with rotary rubber cup/brush. The abrasive properties of paste vary by content and size of paste. However, fine-grained paste can be more abrasive than a thickgrained paste, because there is no standard in abrasiveness of paste among manufacturers.

In our study, it was studied that prophylaxis paste and air-flow powder were provided to be completely the same properties in order to be able to eliminate the effects of abrasive powder used in air-polishing techniques on the amount of abrasion. Therefore, the same paste and powder products having the same contents and produced by the same manufacturer were used for testing. In this way, it was evaluated if the application of the products having the same abrasive properties with the rotary instruments and aerator devices affected on surface roughness. According to the statistical analysis of data, it was determined that reduction observed in roughness values of prophylaxis paste group has been significant.
Another material tested in our study is stainbuster burs. Studies on the effect of burs on hard tooth tissues and especially surface roughness are not sufficient on the literature. For comparing the effects of bur on surface roughness, it was preferred air-polishing method that was known to leave rough surfaces and the prophylaxis paste that was the most commonly used in clinics.

While comparing the materials, polishing application was made only in the enamel surface in each group, thus it was provided that different degrees of abrasion observed on cement and dentin did not affect the result of the study, and the roughness was evaluated only on the enamel surface.

Although some loss of tooth structure was observed in the reports on air-powder instruments, there were also studies showing that the surface became surprisingly smooth $[20,27]$. In our study, while it was observed a smooth appearance on half of the tooth in group applied air-flow and polishing in average, the surface roughness increased in the other half, in line with the other studies showing the harmful effects of air-polishing systems [21,23,27-29]. Although polishing applications were only limited to the enamel surface in our study, this result emerged showed that air-polishing could lead to the opposite results with the philosophy of polishing application, even though it was applied on the enamel surface.

In our study, it was discovered statistically significant decrease in the group which we applied prophylaxis paste. This result is in line with the studies recommending the polishing application following scaling and root planning processes. However, our study supports the argument that application by the rotary rubber is more effective option in reducing the surface roughness independently of the grain size, because prophylaxis paste that was used in paste application done by rotary rubber cup and the powder that was used in air-flow instrument were manufactured by the same manufacturer and they had the same grain size $[5,6,30-32]$.

In our study, stainbuster, the new material intended to be evaluated by comparing the efficacy was also reduced the surface roughness in a statistically significant way. There was no sufficient study related to this material. Studies on roughness have been designed with regard to restorative materials.

\section{Conclusion}

As a result, repeated polishing processes have iatrogenic effects occurring depending on increasing the life time of the teeth. Careful selection of patients who polishing will be applied will reduce the complications and adverse effects.

Our study tries to be a scientific guide for the clinical application of polishing processes. According to the results of our study, 
stainbuster burs are seen as an alternative to traditional polishing materials, because it provides smooth surfaces like prophylaxis paste and ease of application like air-polishing technique.

\section{Compliance with Ethical Standards}

\section{Conflict of interest}

Author Neyran TUZCEL declares that she has no conflict of interest. Author Murat AKKAYA declares that he has no conflict of interest. Author Fatma KARACAOGLU declares that she has no conflict of interest.

\section{Funding}

There is no source of funding this study.

\section{Ethical approval}

All procedures performed in study were in accordance with the ethical standards of the institutional research committee and with the 1964 Helsinki declaration and its later amendments or comparable ethical standards.

\section{Informed consent}

Verbal informed consent was obtained from all individual participants included in the study. 


\section{References}

1 WHO expert Committee (1984) Prevention methods and programs for oral diseases. Technical Report, series 713. Geneva: World Health Organization.

2 Waldman HB (1989) Dentistry in USA: A lesson in survival. J Dent 17 124-131.

3 Leitão J, Hegdahl T (1981) On the measurements of roughness. Acta Odontol Scand 39: 379-384.

4 Leknes KN, Lie T (1988) Erythrosine staining in clinical disclosure of plaque. Quintessence Int 19: 199-204.

5 Zampa ST, Green E (1976) Effect of polishing agents on the root roughness. J Periodontol 43: 125-126.

6 Walker SL, Ash MM Jr (1976) A study of root planning by scanning electron microscopy. ADHA 50: 109-114.

7 Ramfjord S, Ash MM Jr (2015) Periodontology and Periodontics. Philadelphia, WB sounders Company.

8 Sawai MA, Bhardwaj A, Jafri Z, Sultan N, Daing A (2015) Tooth polishing: The current status. J Indian Soc Periodontol 19: 375-380.

9 Rateitscha KH (1994) Failure of periodontol treatment. Quintessence Int 25: 449-457.

10 Meyer K, Lie T (1977) Root surface roughness in response to periodontal instrumentation by combined used of micro roughness measurements and scanning electron microscopy. J Clin Periodontol 4: 77-91.

11 Badersten A, Nilvus R, Egelberg J (1981) Effect of nonsurgical periodontal therapy. I. Moderately advanced periodontitis. J Periodontol 8: 57-72.

12 Torfason T, Kiger R, Selvig KA, Edelberg J (1979) Clinical improvement of gingival conditions following ultrasonic versus hand instrumentation of periodontal pockets. J Clin Periodontol 6: 165-75.

13 Badersten A, Nilvus R, Egelberg J (1984) Effect of nonsurgical periodontal therapy. II. Severally advanced periodontitis. J Clin Periodontol 11: 63-76.

14 Loos B, Kiger R, Edelberg J (1987) An evaluation of basic periodontal therapy using sonic and ultrasonic scalers. J Clin Periodontol 14: 29-33.

15 Biagini G, Checci L, Miccoli MC, Vasi V, Castaldini C (1988) Root curettage and gingival repair in periodontitis. J Periodontol 59: 124-129.

16 Scwartz JP, Guggenheim R, Düggelin M, Hefti AF, Rateitschak-Plüss $E M$, et al. (1989) The effectiveness of root debridement in open flap procedures by means of a comparison between hand instruments and diamond burs. A SEM study. J Clin Periodontol 16: 510-518.
17 Ritz L, Hefti AF, Rateischak KH (1991) An in vitro investigation on the loss of root substance in scaling with various instruments. J Clin periodontal 18: 643-647.

18 Gantes BG, Nilvus R, Lie T, Leknes KN (1992) The effect of hygiene instruments on dentin surfaces: scanning electron microscopic observations. J Periodontol 63: 151-157.

19 Weaks LM, Lescher NB, Barnes CM, Holroyd SV (1984) Clinical evaluation of the Prophy-Jet as an instrument for routine removal of tooth stain and plaque. J Periodontol 55: 486-488.

20 Berkstein S, Reiff RL, McKinney JF, Killoy WJ (1987) Supragingival root surface removal during maintenance procedures utilizing an airpowder abrasive system or hand scaling. J Periodontol 58: 327-329.

21 Horning GM, Cobb CM, Killoy WJ (1987) Effect of an air-powder abrasive system on root surfaces in periodontal surgery. J Clin Periodontol 14: 213-220.

22 Barnes CM, Russel CM, Gerbo LR, Wells BR, Barnes DW (1990) Effects of an air-powder polishing system on orthodontically bracketed and banded teeth. Am J of Orthod Dento-facial Orthop 97: 74-81.

23 Kontturi-Närki V, Markkanen S, Markkanen H (1990) Effects of air polishing on dental plaque removal and hard tissue as evaluated by scanning electron microscopy. J Periodontol 61: 334-338.

24 Mahledorff M (1989) Evaluation of the relationships between abrasion and surface alterations after professional cleaning. Deutsche Zahnärztliche Zeitschrift 44: 203-204.

25 Petersilka GJ, Bell M, Häberlein I, Ehl A, Hickel R, et al. (2003) In vitro evaluation of novel low abrasive air polishing powders. J Clin Periodontol 30: 9-13.

26 Jost-Brinkmann PG (1998) The influence of air polishers on tooth enamel. An in vitro study. J Orofacial Orthopedics 59: 1-16.

27 Atkinson DR, Cobb CM, Killoy WJ (1984) The effect of an air-powder abrasive system on in vitro root surfaces. J Periodontol 55: 13-18.

28 Agger MS (2001) Abrasiveness of an air-powder polishing system on root surfaces in vitro. Quintessence's Int 32: 407-411.

29 Boyde A (1984) Air polishing effects on enamel, dentine, cement and bone. Br Dent J 156: 287-91.

30 Doyle PT The polishing effect of the EVA system and dental tape. Thesis $\neq 665$, Ann Arbor, The University of Michigan.

31 Lutz F, Sener B, Imfeld T, Barbakow F, Schüpbach P (1993) Self adjustig abrasiveness: A new technology for prophylaxes pastes. Quintessences Int 24: 53-63.

32 Lutz F, Sener B, Imfeld T, Barbakow F, Schüpbach P (1993) Comparison of the efficacy of prophylaxis pastes with conventional abrasives or a new self-adjusting abrasive. Quintessences Int 24: 193-201. 